\title{
Urology at your fingertips: the development of a urology m-learning app for medical students
}

\author{
Kevin Gerard Keane ${ }^{1 \wedge}$, Nikita Rajiv Bhatt ${ }^{1}$, Patrick Michael Collins ${ }^{1}$, Robert Joseph Flynn ${ }^{1,2}$, \\ Rustom Pervez Manecksha ${ }^{1,2}$ \\ ${ }^{1}$ Department of Urology, Tallaght University Hospital, Dublin, Ireland; ${ }^{2}$ Department of Surgery, School of Medicine, Trinity College Dublin, \\ Dublin, Ireland \\ Contributions: (I) Conception and design: RP Manecksha, RJ Flynn, NR Bhatt, KG Keane; (II) Administrative support: RP Manecksha; (III) Provision \\ of study materials or patients: RP Manecksha, KG Keane; (IV) Collection and assembly of data: RP Manecksha, KG Keane, PM Collins; (V) Data \\ analysis and interpretation: KG Keane; (VI) Manuscript writing: All authors; (VII) Final approval of manuscript: All authors. \\ Correspondence to: Kevin Gerard Keane. Graigue, Adare, Co. Limerick V94H01R, Ireland. Email: Kevin.keane@ucdconnect.ie.
}

\begin{abstract}
Background: Surgical education has embraced advancing technology with an emphasis on e-learning in recent years. Smartphones are a useful tool for medical teaching and learning with increasing use by medical students to access e-books, medical calculators, podcasts, and medical applications (apps). Our aim was to develop a dedicated urology app for medical students as an adjunct to traditional teaching.

Methods: We published an e-book: Urology Handbook for Medical Students in 2017 based on the core urology curriculum for medical students. Subsequently, we developed a concise, simple and user-friendly smartphone app for medical students called "Urology Med", available for download on App Store and Google Play.

Results: This app is an introduction to urology for medical students but may also be useful for interns and surgical trainees. The app encompasses core urology topics subdivided into common urological presentations, urological examination, urological diseases, and urological devices. To make the app interactive, it includes 5 clinical cases that complement the reading material and six quizzes for self-assessment. A comprehensive checklist of 31 "must see" and "good to see" urology experiences is included. Within one month of launch, the app was downloaded 435 times in five countries across three continents. It has a 5 -star rating on the Apple store.

Conclusions: High educational standards with relevant content make e-learning a valuable learning tool for surgical education. The Urology Med app facilitates easy access to urology and is ideal for quick reading while working or revising.
\end{abstract}

Keywords: Smartphone; application (app); urology; medical students; education; surgery

Submitted Sep 08, 2020. Accepted for publication Jan 18, 2021.

doi: $10.21037 /$ tau-20-1245

View this article at: http://dx.doi.org/10.21037/tau-20-1245

\section{Introduction}

Over the last decade the use of computer technology has increased immeasurably, with smartphones becoming ubiquitous in society. They have transformed the way we communicate both in our personal and professional lives.
The medical profession has been quick to embrace this development, so much so that a new term has been created to describe the use of mobile devices for health purposes; mobile Health, or mHealth (1). M-learning is the expression used to describe the use of mobile devices for educational. It is estimated that m-learning is used in the education of

$\wedge$ ORCID: 0000-0002-4963-4325. 
medical students and doctors in over $84 \%$ of countries (1).

The landscape of medical education has been transformed in recent years, with a shift in paradigm from traditional didactic lectures to e-learning, and more recently m-learning. Smartphones are a useful tool for surgical teaching with increasing use by doctors and medical students to access e-books, medical calculators, drug formularies, podcasts and medical applications (apps). The advantages are plentiful; smartphones are small, portable, convenient and provide instant access to infinite amounts of information. They allow a dynamic platform for multimedia learning through apps which contain text, illustrations, videos and podcasts.

The demand for new teaching apps by medical students has already been well established in several studies (2-8). The concept of evidence-based medicine ensures that lifelong learning is now mandatory for those embarking on medical and surgical careers. With such enormous quantities of ever evolving information to comprehend, m-learning represents a convenient and interactive teaching method for medical students to keep abreast of new developments in the discipline, and gives new meaning to the common medical phrase "take your tablets".

A review of mHealth in Urology in 2015 identified 150 urology specific apps and established that $20 \%$ of urology apps did not have expert input in development, a lower number compared to apps for other surgical specialties (9). They concluded that, although smartphone app technology has the potential to enrich education in urology, further participation by specialists in app design and content was needed to ensure high quality reliable and information is provided. These findings were echoed by Shapiro et al. in 2019 (10).

With this in mind, our aim was to develop a concise, accurate, simple and user-friendly app on urology for medical students designed by a consultant urologist. We intend for the app to serve as an ideal first introduction to urology for all medical students, interns/foundation year doctors and new surgical trainees and supplement clinical teaching.

\section{Methods}

We published an e-book: Urology Handbook for Medical Students in 2017 based on the core urology curriculum for medical students (11). Subsequently, in 2020 we developed a urology education app for medical students. The app was privately funded and designed by a software engineer for both Android and Apple platforms using Google Flutter@. App content was developed by a consultant urologist and urology trainee. Student's reception of the app was elicited using both focus groups and questionnaires.

Over a 6-month period, medical students rotating through the Urology Department in a tertiary Irish hospital were given access to the app for the duration of their placement. On completion of their urology rotation, they were asked to fill out an anonymous survey assessing the app. All responses were recorded in a departmental database. Primary outcomes assessed were clinical relevance, user friendliness and overall satisfaction. Additionally, a focus group was conducted with ten medical students to examine how, when and where the app was being used, to identify any problems with the existing version of the app, and to gather feedback and recommendations that could be used to enhance future app updates.

\section{Results}

We developed a concise, simple, and user-friendly smartphone app called "Urology for Medical Students", available for download on App Store and Google Play $(12,13)$. Our app is listed on the "Urology Apps for Medical Students" section on the British Association of Urological Surgeons (BAUS) website (14). To date our app has been downloaded 439 times in five different countries, and is rated 5/5 stars on App Store (Figure 1) (12).

The app is presented as a simple interface divided into four sections: "Reading Material", "Clinical Cases", "Urology Checklist", and "Quiz". To maximise accessibility, the app is available in offline mode and thus can be used even in the setting of unreliable internet connection.

\section{Reading material}

This section covers all the major urological topics in the curriculum for medical students as advised by various urology associations like BAUS and the American Urological Association (AUA). It is divided into "Common Urological Presentations", "Urological Examination", "Urological Diseases" and "Urological Devices" (Figure 2). Multimedia content including plain text, original diagrams and tables, and medical imaging is incorporated to appeal to all learning styles.

\section{Clinical cases}

The app contains five clinical cases designed to replicate practical scenarios that students might face during their urology rotation (Figure 3). This section allows students 

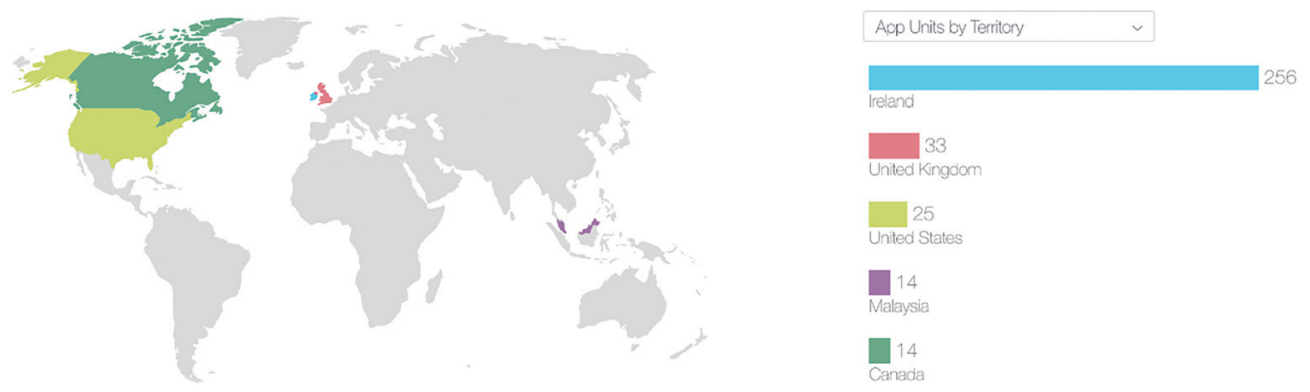

Figure 1 Geographical distribution of app download.

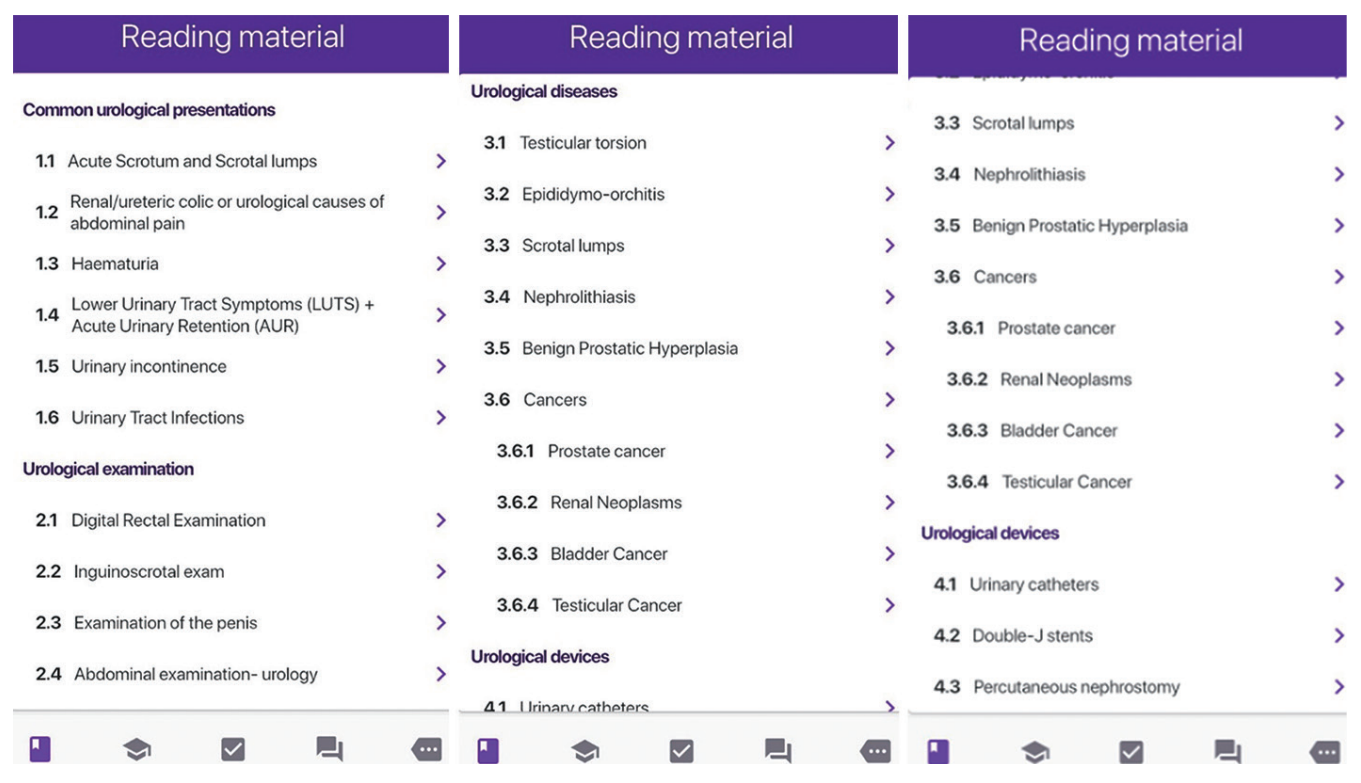

Figure 2 Reading material.

contextualise knowledge assimilated in the "Reading Material" and apply it to a real-life patient encounter on urology. Cases are presented in a step-by-step fashion from initial presentation to differential diagnosis, work-up and management (Figure 4). The student must think about each step in the scenario and answer questions before progressing further in the case.

\section{Urology checklist}

We designed a checklist of common urological presentations, diseases, procedures and equipment that were deemed beneficial for students to experience during their clinical rotation. This allows students clearly understand the expected objectives of their rotation. These items cover ward/ outpatient experiences as well as theatre/procedure-based encounters (Figure 5). Students can physically tick the item off their list once completed, allowing them to know they are meeting the goals of the rotation in real time.

\section{Quiz}

This section includes self-assessments on six key urological themes. The objective of the quiz is for students to consolidate the information obtained in the previous sections. Each quiz contains between 1 and 10 multiple choice questions (Figure 6). Students can view the correct answers and re-attempt the quiz if desired.

A total of 60 medical students rotated through the urology department over a 6-month period. The response 


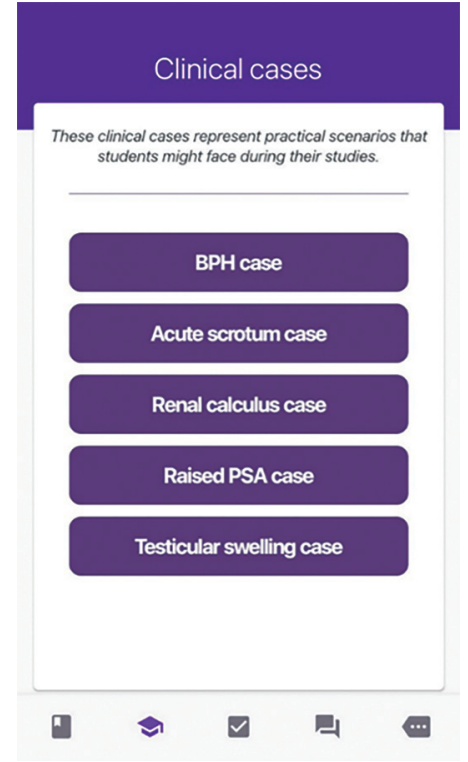

Figure 3 Clinical cases.

rate of the post-rotation survey was $93 \%(n=56)$. All respondents thought the app positively enhanced their learning experience whilst on urology rotation. The majority of medical students $(n=54)$ used the app as an adjunct to traditional teaching, and $92 \%$ of students $(n=51)$ would like to see similar educational apps developed and made available in other medical specialties. All students $(\mathrm{n}=56)$ rated the app 10/10 for user friendliness and believed the app met their clinical needs, with $88 \%$ of students $(n=49)$ stating that the content provided was appropriate for their level of study.

A focus group was held with ten medical students to gather overall feedback about the app. The session was conducted by a moderator and transcribed by an assistant moderator. Focus group questions were centred on user friendliness, patterns of app use, issues with the current version of the app and advice for future updates. From the group discussion it became apparent that the convenience of having a portable source of relevant urology content whilst on urology rotation was what students valued most about the app; "I particularly enjoyed being able to open the app whilst waiting for a case to start in theatre, or after seeing an interesting patient on a ward round, and read up on the area in question straight away", "I used the app on the bus on the way to the hospital -it was great to have all I needed to know on my phone and not to have to carry around a beavy book while I was in the hospital".

The app was universally well received in terms of user friendliness; "It was very easy to find the information I was looking for quickly and switch between the different sections. The checklist section was very beneficial, it allowed me to know what was expected of me and where the gaps were in my urology experience so I could then try and address them in real time". Students did not identify any significant issues with the current version of the app; however, they did make some recommendations for future edits: "My favourite section was the quiz section-I loved testing myself after the reading materiel or even sometimes before it to gauge my knowledge level. If possible, more quiz questions/topics would be welcome", "I think the addition of pictures to the urological device section would be useful-sometimes we came across various urology equipment but didn't recognise them for what they were at the time, e.g., nephrostomy".

\section{Discussion}

There is a plethora of urological apps available to download on smartphones for patients and healthcare providers alike. Patient education and self-management apps such as prostate-specific antigen (PSA) trackers, pelvic floor exercise guides and bladder diaries have been developed in an effort to empower patients, increase awareness and improve symptoms. For urologists, electronic urology journals, guidelines by urological associations, prostate cancer prognostic nomograms, urology conference programmes and ureteric stent trackers have been developed.

The use of urology apps as educational tools signifies an innovative and exciting advancement in the development of urological education. A study by Nason et al. in 2014 examined the use of smartphone apps amongst Irish urology trainees and found that $77 \%$ of respondents used urology apps for educational purposes, with the vast majority considering them useful or very useful (15). The average number of urology apps downloaded per trainee was 4, with the most commonly utilised apps including E-logbook (75\%), the Oxford Handbook of Urology (47\%), EAU Conference App (36\%), Urology Flashcards (21\%), and National Comprehensive Cancer Network Guidelines (14\%) (15).

Medical students are also increasingly using this novel educational resource for learning. In 2015, Payne et al. conducted a survey of 203 undergraduate medical students examining the pattern of smartphone and medical related app use (6). Over half of respondents owned between 1 and 5 medical apps, with $41.6 \%$ of students on clinical attachments using these apps more than once a day. 


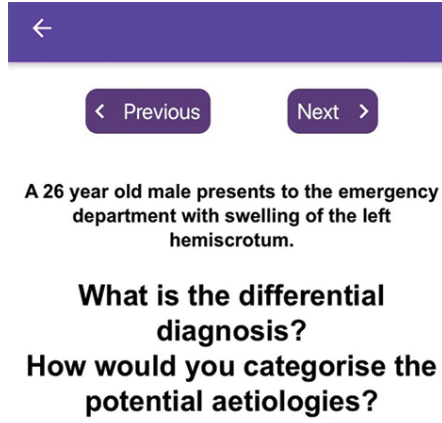

$\leftarrow$

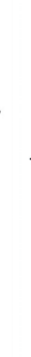

$\leftarrow$

<Previous Next >

Differential diagnosis Testicle

- Infection - Epididymo-orchitis

- Tumour - Testicular cancer

- Trauma - Testicular haematoma, testicular rupture

- Mechanical - Testicular torsion, testicular appendage torsion

Scrotum

- Infection - Scrotal cellulitis, scrotal abscess

- Varicocoele

- Hydrocoele

Bowel

- Inguinal hernia

\section{$\leftarrow$}

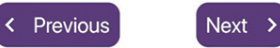

What questions would you ask

to narrow the differential diagnosis?

Figure 4 Scrotal swelling clinical case.

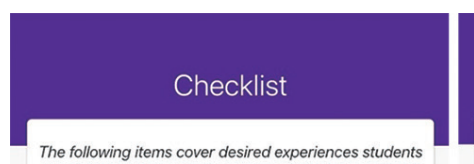

should corg hens cover desired experiences students should cover during their urology rotation. These items cover both ward/outpatient-based experience, and

"Should see" - procedures students should have observed (ask to scrub in where possible) and common presentations students are expected to be familiar with. "Good to see" - procedures that would be beneficial/of would be useful.

\section{Must see}

$\square \quad$ Acute ureteric colic

$\checkmark$ Haematuria

$\square \quad$ Lower urinary tract symptoms

$\square \quad$ Urinary retention

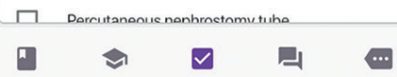

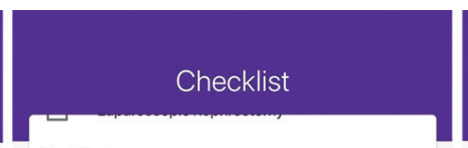

Good tosee

Renal trauma

Bladder trauma

Testicular trauma

Acute scrotal pain (e.g. torsion vs epididymo-

orchitis)

Testicular tumour

Suprapubic catheter insertion

Urodynamics

ESWL

Manual bladder washout

Percutaneous renal stone surgery

Robotic-assisted laparoscopic surgery

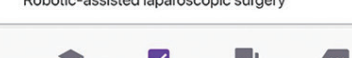

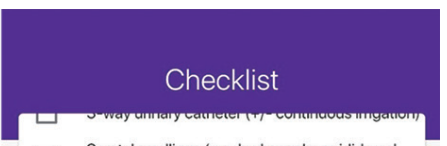

Scrotal swellings (e.g. hydrocoele, epididymal cyst vs hernia)

$\square \quad$ Peritoneal dialysis catheter

Renal transplant

Scars

Urethral catheterisation

Cystoscopy

Ureteroscopy

Hydrocoele repair

Circumcision

Transurethral surgery for bladder tumour

Transurethral surgery for BPH

Laparoscopic nephrectomy

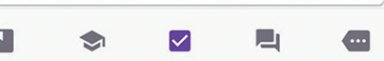

Figure 5 Urology checklist.

Students expressed interest in apps that outline module objectives and quiz type revision apps. Also of importance to students was app affordability within the provisions of tight student budgets. Almost all participants said they would download an app specific to their medical school if available. A similar study in 2016 showed that $85 \%$ of students use medical apps for learning and $93 \%$ finding these apps contribute significantly to their education. Nearly all students expressed desire for further educational apps to be developed (16). Students also cite a reduction in wasted time as a major advantage to the smartphone. The portable convenient smartphone allows for timely access to information on occasions when traditional learning through textbooks would not be possible, such as on the wards, in theatre or even in a shop queue.

Based on the aforementioned demand for expert designed educational apps, we embraced m-learning by developing a concise, dynamic, intuitive urology app for 


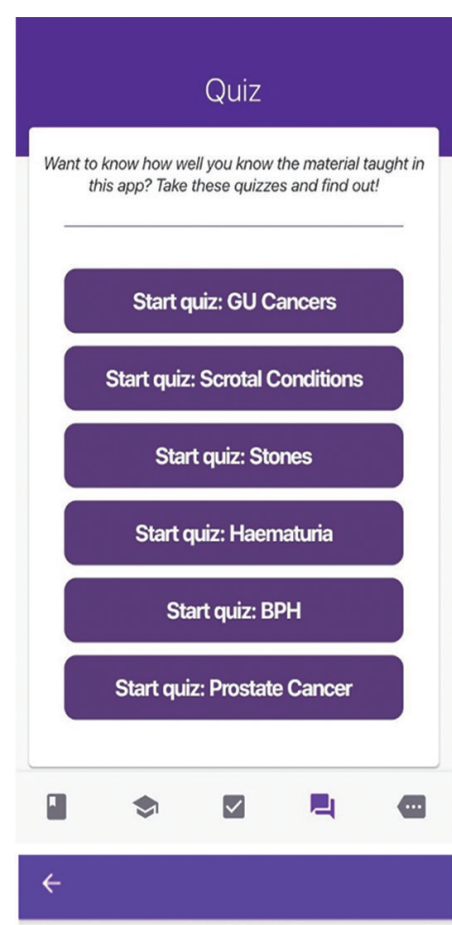
PSA can be raised in which of the following
cases?

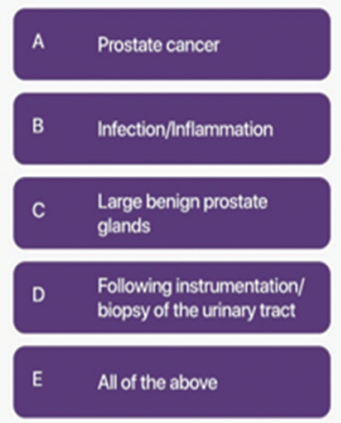

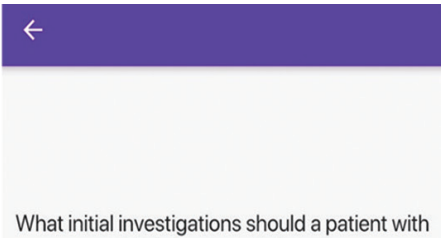
visible haematuria have?

A MSU and urine culture

B Flexible cystoscopy

C Renal profile and full blood count

D Upper tract imaging (US renal tract or CT Urogram)

E All of the above

\section{$\leftarrow$}

If US renal tract was normal in a patient with ongoing visible haematuria which imaging study is most appropriate to further assess?

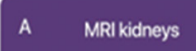

B $\quad$ CT KUB (non-contrast)

C MAG 3 scan

D Cr Urogram (with contrast)

Figure 6 Quiz.

medical students. Our app is ideal for quick reading whilst working or revising and allows medical students to always have urology at their fingertips. There are few other urology apps specifically designed for medical students and most of these focus heavily on the use of video teaching. Whilst undeniably useful resources, apps that use videos for teaching are not always suitable for quick reference in clinical environments and occasionally it can take a long time to locate the specific information one is looking for.
Our app differs to what is currently available as its primary focus is to serve as a reference tool whilst on urology clinical rotation. It is predominantly text-based, with the use of hyperlinking to easily navigate between sections. Furthermore our 'Urology Checklist' provides students with clear objectives for their rotation, with the "Clinical Case" and "Quiz" sections designed to contextualise clinical learning on the rotation.

Apart from the obvious demand for medical education 
apps there is emerging evidence that m-learning can be as, if not more, effective than traditional methods to support clinical learning. Davies et al. developed a framework of how m-learning facilitates education in medical students on clinical rotations (5). Their model describes how an initial trigger identifies a knowledge deficit (e.g., bedside interaction with a patient who has prostate cancer). The smartphone is then used immediately to access the relevant information which is contextualised within the clinical scenario (e.g., our apps reading material on prostate cancer). Consolidation is achieved through repetition of this process and reflection (using our clinical case and quiz sections on prostate cancer).

Multiple papers have shown the positive impact of m-learning on medical student education (3,17-19). Two papers have reported improved performance in medical examinations following introduction of m-learning apps $(20,21)$. Alipour et al. compared teaching of breast cancer using a book compared to a mobile device and found that m-learning resulted in higher knowledge acquisition and generated more interest amongst students (22). Importantly, two randomised controlled trials have suggested the importance of m-learning in medical education. Low et al. showed significantly better performances in a medical emergency by doctors who had access to the smartphone app iResus ${ }^{\odot}$ compared to similarly qualified doctors who had only undergone traditional Advanced Life Support training (23).

There are potential drawbacks to the use of smartphones for m-learning in medicine, including over-dependence, dilution of the trainer-trainee relationship, the possibility for distraction by other apps. Furthermore, there currently exists no form of central regulation of mHealth apps, allowing for the creation of inaccurate or unreliable apps (24).

Our "Urology for Medical students" app is designed to complement and augment clinical teaching and not to replace it. M-Learning in urology is constantly evolving and there are multiple avenues of exploration to add to our app to ensure it remains relevant and accurate. Future improvements of our app may include addition of video tutorials and brief educational podcasts.

\section{Conclusions}

With the emergence of COVID-19 m-learning looks set to become even more important and it is clear that smartphone apps represent an increasingly significant clinical resource in surgical education. We hope publication of our work will help increase awareness of the "Urology for Medical Students" app and enhance student experience on their urology rotation.

\section{Acknowledgments}

Special thanks to Prof Rustom P. Manecksha and Prof Robert J. Flynn, Consultant Urological Surgeons, Tallaght University Hospital.

Funding: None.

\section{Footnote}

Data Sharing Statement: Available at http://dx.doi. org/10.21037/tau-20-1245

Conflicts of Interest: All authors have completed the ICMJE uniform disclosure form (available at http://dx.doi. org/10.21037/tau-20-1245). The authors have no conflicts of interest to declare

Ethical Statement: The authors are accountable for all aspects of the work in ensuring that questions related to the accuracy or integrity of any part of the work are appropriately investigated and resolved.

Open Access Statement: This is an Open Access article distributed in accordance with the Creative Commons Attribution-NonCommercial-NoDerivs 4.0 International License (CC BY-NC-ND 4.0), which permits the noncommercial replication and distribution of the article with the strict proviso that no changes or edits are made and the original work is properly cited (including links to both the formal publication through the relevant DOI and the license). See: https://creativecommons.org/licenses/by-nc-nd/4.0/.

\section{References}

1. World Health Organization. Global diffusion of eHealth: making universal health coverage achievable: Report of the third global survey on eHealth. World Health Organization, 2016.

2. Wernhart A, Gahbauer S, Haluza D. eHealth and telemedicine: Practices and beliefs among healthcare professionals and medical students at a medical university. PloS One 2019;14:e213067.

3. Gormley GJ, Collins K, Boohan M, et al. Is there a place for e-learning in clinical skills? A survey of undergraduate 
medical students' experiences and attitudes. Med Teach 2009;31:e6-12.

4. Chase TJG, Julius A, Chandan JS, et al. Mobile learning in medicine: an evaluation of attitudes and behaviours of medical students. BMC Med Educ 2018;18:152.

5. Davies BS, Rafique J, Vincent TR, et al. Mobile Medical Education (MoMEd) - how mobile information resources contribute to learning for undergraduate clinical students a mixed methods study. BMC Med Educ 2012;12:1.

6. Payne KB, Wharrad H, Watts K. Smartphone and medical related App use among medical students and junior doctors in the United Kingdom (UK): a regional survey. BMC Med Inform Decis Mak 2012;12:121.

7. Robinson T, Cronin T, Ibrahim H, et al. Smartphone use and acceptability among clinical medical students: a questionnaire-based study. J Med Syst 2013;37:9936.

8. Gavali MY, Khismatrao DS, Gavali YV, et al. Smartphone, the New Learning Aid amongst Medical Students. J Clin Diagn Res 2017;11:JC05-JC08.

9. Pereira-Azevedo N, Carrasquinho E, Cardoso de Oliveira E, et al. mHealth in Urology: A Review of Experts' Involvement in App Development. PloS One 2015;10:e0125547.

10. Tapiero S, Yoon R, Jefferson F, et al. Smartphone technology and its applications in urology: a review of the literature. World J Urol 2020;38:2393-410.

11. Bhatt N, Manecksha R, Flynn R. Urology Handbook for Medical Students. 1st edition. SELF, 2017.

12. Store A. Urology for Medical Students. Available online: https://apps.apple.com/us/app/urology-for-medicalstudents/id1479582795

13. Urology Med. Available online: https://play.google. com/store/apps/details?id=com.urologydeptdublin. ebook\&hl=en_IE

14. The British Association of Urological Surgeons. Urology Apps for Medical Students. Available online: https://www.

Cite this article as: Keane KG, Bhatt NR, Collins PM, Flynn RJ, Manecksha RP. Urology at your fingertips: the development of a urology m-learning app for medical students. Transl Androl Urol 2021;10(3):1152-1159. doi: 10.21037/tau-20-1245 baus.org.uk/professionals/sections/urology_apps.aspx

15. Nason GJ, Burke MJ, Aslam A, et al. The use of smartphone applications by urology trainees. Surgeon 2015;13:263-6.

16. Snashall E, Hindocha S. editors. The Use of Smartphone Applications in Medical Education. Open Med J 2016;3:322-7.

17. Green BL, Kennedy I, Hassanzadeh H, et al. A semiquantitative and thematic analysis of medical student attitudes towards M-Learning. J Eval Clin Pract 2015;21:925-30.

18. Law JK, Thome PA, Lindeman B, et al. Student use and perceptions of mobile technology in clinical clerkships - Guidance for curriculum design. Am J Surg 2018;215:196-9.

19. Alegría DA, Boscardin C, Poncelet A, et al. Using tablets to support self-regulated learning in a longitudinal integrated clerkship. Med Educ Online 2014;19:23638.

20. Smeds MR, Thrush CR, Mizell JS, et al. Mobile spaced education for surgery rotation improves National Board of Medical Examiners scores. J Surg Res 2016;201:99-104.

21. Baumgart DC, Wende I, Grittner U. Tablet computer enhanced training improves internal medicine exam performance. PLoS One 2017;12:e0172827.

22. Alipour S, Moini A, Jafari-Adli S, et al. Comparison of teaching about breast cancer via mobile or traditional learning methods in gynecology residents. Asian Pac J Cancer Prev 2012;13:4593-5.

23. Low D, Clark N, Soar J, et al. A randomised control trial to determine if use of the iResus(C) application on a smart phone improves the performance of an advanced life support provider in a simulated medical emergency. Anaesthesia 2011;66:255-62.

24. Franko OI, Tirrell TF. Smartphone app use among medical providers in ACGME training programs. J Med Syst 2012;36:3135-9. 